\title{
Dynamic Impact Response of Ultrafine Grained AA5052 Aluminum Alloy Processed Via Multiaxial Forging at Cryogenic Temperature
}

\author{
O. J. Ajao ${ }^{\text {a }}$ G. M. Owolabi ${ }^{\text {, H.A. Whitworth }}{ }^{\mathrm{c}}$, O. Scott-Emuakpor ${ }^{\mathrm{d}}$ \\ a,b,c Department of Mechanical Engineering, Howard University, Washington DC, USA, \\ ${ }^{\mathrm{d}}$ Aerospace Systems Directorate (AFRL/RQTI), Wright-Patterson AFB, OH 45433 \\ a oluwafemi.ajao@bison.howard.edu, b gbadebo.owolabi@howard.edu, ${ }^{\mathrm{c}}$ hwhitworth@ howard.edu, ${ }^{\mathrm{d}}$ onome.scott- \\ emuakpor.1@us.af.mil
}

Article History: Received: 10 November 2020; Revised 12 January 2021 Accepted: 27 January 2021; Published online: 5 April 2021

\begin{abstract}
In this study, high strain rate mechanical test was conducted on ultrafine-grained AA5052 aluminum alloy using the Split-Hopkinson Pressure Bar experiment. The AA5052 aluminum alloy was processed via multiaxial forging under cryogenic condition at two different cycles to achieve grain refinement and ultimately, increase in strength of the material. The average strain rates that the specimens were subjected to during the Split-Hopkinson Pressure Bar experiment ranges from $1000 \mathrm{~s}-1$ to $5000 \mathrm{~s}-1$ at an increment of $1000 \mathrm{~s}-1$. The EBSD map shows that the average grain size of the AA5052 aluminum alloys for the samples processed at 4-cycles is approximately $\sim 900 \mathrm{~nm}$ while the samples processed at 6-cycles have a lower average grain size of approximately $\sim 700 \mathrm{~nm}$ due to being subjected to more plastic deformation during the processing. The high strain rate deformation process of both specimens was dominated by thermal softening with minima strain hardening effect. During the deformation, the maximum flow stress experienced by samples that was processed at 4-cycles is $410 \mathrm{MPa}$ at $5000 \mathrm{~s}-1 \mathrm{strain}$ rate while samples processed at 6-cycles has $494 \mathrm{MPa}$ at $3000 \mathrm{~s}-1$. Strain hardenability is not dominant in the deformation mechanism but relative to AA5052 CF (4-cycles), AA5052 CF (6-cycles) has a better strain hardening exponent as the strain rate increases. Both specimens have the highest strain hardening exponent at $1000 \mathrm{~s}-1$ which is 0.1544 and 0.134 for AA5052 CF (4-cycles) and AA5052 CF (6-cycles), respectively. Our results show that AA5052 CF (6-cycles) possesses better mechanical properties under high strain rate in comparison with AA5052 CF (6-cycles).
\end{abstract}

Keywords: AA5052 Aluminum Alloy, Cryogenic Forging, Split-Hopkinson Pressure Bar, Ultrafine Grained

\section{Introduction}

A lot of interest has been shown in the production of ultrafine grained materials (UFG) in recent years due to the unique physical and mechanical properties that is obtainable in UFG. The grain size and average diameter of grains in a polycrystalline metal have great influence on the mechanical properties of such polycrystalline metal [1]-[3]. The smaller the grain size of a material, the stronger and harder the material becomes because there is presence of more grain boundaries to impede dislocation motion [4]. Grain size reduction also increases the toughness of the materials. All this increaseis done at the expense of the ductility of the material [1].

UFG materials are structural materials with grain sizes in the sub-micrometer or nanometer range and they typically exhibit high strength/low ductility (HSLD). By processing the material to a very high strain and/or applying short term annealing, it is possible to achieve high strength/high ductility (HSHD). Reducing the grain size of the bulk material using thermomechanical processing operation is the key to achieving high yield strength. The variation of the yield strength $\sigma_{y}$ with grain size for most material is given by Hall-Petch equation [1],[5].

$$
\sigma_{y}=\sigma_{0}+k_{y} d^{-1 / 2}
$$

where $\sigma_{0}$ is a materials constant for the starting stress for dislocation movement (or the resistance of the lattice to dislocation motion), $k_{y}$ is the strengthening coefficient (a constant specific to each material), and $d$ is the average grain diameter.Equation (1) is valid when the material is at low temperature usually up to $\sim 0.5 T_{m}$ where $T_{m}$ is the absolute melting temperature [5].

Most of these UFG materials are produced through severe plastic deformation (SPD) process which involves very large deformations at relatively low temperatures and under high pressure [4],[5]. A review of different SPD processes can be found in [2],[3],[6]-[10]. SPD processing basically involves imposing very high strain on the material without any significant change in the dimensions of the sample. Equal-channel angular pressing (ECAP) is relatively easy to use and high-pressure torsion (HPT) yields materials with small grain sizes as well as high fraction of high angle grain boundary therefore both methods have been the most used SPD techniques [11]- 
[16].Cryo-rolling/cryo-forging helps to produce ultrafine grains in pure $\mathrm{Al}$ with less pressure when compared with other SPD processes [17],[18]. This is largely due to the suppression of the dynamic recovery during the cryorolling. The dynamic recovery is reduced to the minimum during cryo-rolling/forging due to the suppression of cross slip and climb dislocation. This in turn makes the dislocation density to remain high and the corrosion resistance considerably decreases [19]. The high stacking fault energy associated with conventional rolling process makes it impossible to produce UFG Al alloys. Another advantage of cryo-rolling/forging over conventional rolling is that the former requires less plastic deformation relative to the latter [19]. Another trade-off among the properties of cryo-rolled $\mathrm{Al}$ alloys is the reduction in ductility with an increase in strength and hardness [19].

The cryo-rolled Al has improved properties in terms of yield strength and tensile strength when compared with the commercially pure Al [17]. The hardness, tensile strength, and strain rate sensitivity (SRS) of multi axially forged

Table 1: Chemical composition of the AA5052 aluminum alloy (wt.\%)

\begin{tabular}{lllllllll}
\hline Elements & $\mathbf{M g}$ & $\mathrm{Cr}$ & $\mathrm{Cu}$ & $\mathrm{Fe}$ & $\mathrm{Mn}$ & $\mathrm{Si}$ & $\mathrm{Zn}$ & $\mathrm{Al}$ \\
\hline Composition & $2.2-2.8$ & $0.15-0.35$ & 0.1 & 0.4 & 0.1 & 0.25 & 0.1 & Balance
\end{tabular}

(MAF) $6063 \mathrm{Al}$ alloys at liquid nitrogen temperature was shown to have improved significantly by [18]. For this reason, Multi-axial forging

or simply cryo-forging was selected for producing the UFG material that was used in this study.

Aluminum which exist as the most abundant metal on earth have been used as structural materials due to mechanical properties such as appearance, light weight, fabricability, high specific strength, good machinability, excellent ductility, high corrosion resistance, among others [20]. Some of the commonly used structural metals include carbon steel, aluminum, copper tubing, and stainless steel. When compared to other structural metals listed above, aluminum has a better strength-to-weight ratio which makes it a good candidate material where high strength and relatively lower weight is required. For example, in comparison with steel and copper which has densities of $\sim 7.85 \mathrm{~g} / \mathrm{cm}^{3}$ and $\sim 8.96 \mathrm{~g} / \mathrm{cm}^{3}$ respectively, aluminum has a density of about $\sim 2.7 \mathrm{~g} / \mathrm{cm}^{3}[20]$.

The high strength-to-weight ratio of aluminum alloys makes them to have high applications in aerospace, automobile, and military defense structures. Aluminum 5052 typically has application in aircraft, marine, general sheet metal work, architecture, heat exchangers, fuel lines and tanks, rivets, wires, flooring panels, streetlights, and appliances [20].

Plastic deformation in aluminum and other metals occurs by the mechanism of slip along the crystallographic planes in the grains of the metal [21]. And because aluminum alloys have face-centered cubic structure, it has twelve (12) slip systems which makes it to accommodate lot of plastic deformation thereby enhancing its formability. The slip system of aluminum and other FCC structure is $\{111\}\langle 110\rangle[1]$. About $5 \%$ of the deformation energy is stored as internal energy while the rest is dissipated as heat. The major portion of this stored energy is strain energy that is associated with dislocation. There is always an increase in the number of dislocation during the plastic deformation which is as a result of dislocation multiplication as well as formation of new dislocation through grain boundaries, internal defects, and surface irregularities [1].

There is at present no study in open literature addressing the dynamic behavior of ultrafine-grained (UFG) AA5052 aluminum alloy produced via multiaxial forging under cryogenic temperature or simply cryo-forging. Therefore, this paper presents the high strain rate dynamicmechanical response of UFG AA5052 aluminum alloy prepared by multi-axial forging at cryogenic temperatures.

\section{Materials and Methods}

The chemical composition of the AA5052 aluminum alloy is given in Table 1. The as-received specimen is a plate with rectangular cross section which was homogenized at $500^{\circ} \mathrm{C}$ for $10 \mathrm{~h}$ in a controlled atmosphere of argon, and then quenched in water at room temperature. Finally, the specimen was finally processed through multiaxial forging (MAF).Both cryogenic temperature (liquid nitrogen temperature of $-196{ }^{0} \mathrm{C}$ ) and room temperature were used for the MAF.

This process was also done by repeating the MAF through 4-cycles and 6-cycles at a strain rate of $10 \mathrm{~s}^{-1}$.

For the purpose of storing and pouring the liquid nitrogen, the cryo-can was used while the sample container was used to hold the sample in liquid nitrogen. The MAF process was carried out using the friction screw forging machine. 
The cryogenic MAF process is highlighted with the following points;

i. The samples were dropped in liquid nitrogen for $15 \mathrm{~min}$.

ii. An axial compression strain was applied to the sample using its extrusion direction as the preferred starting forging axis. This makes the first pass.

iii. After quenching the sample in liquid nitrogen, another axial compression was applied along one of the orthogonal directions to the direction that was used in step (ii).

iv. Finally, step (iii) was repeated with the direction changed to the third orthogonal direction.

These steps make a complete cycle. Hence, 4-cycles and 6-cycles means repeating step (i) - (iv) 4-times and 6times, respectively.

Cylindrical test specimen with diameter $D=3 \mathrm{~mm}$ and length $L=3 \mathrm{~mm}$ (aspect ratio L/D $=1$ ) were prepared from the MAF samples using a lathe machine. Split Hopkinson Pressure Bar (SHPB), with strain rate range of $10^{2}$ to $10^{4} \mathrm{~s}^{-1}$, was used to characterize the dynamic response of the material. A typical SPHB, shown in Fig. 1, has the striker bar, the incident bar, the transmitter bar, data acquisition system (strain conditioners/ amplifiers and digital oscilloscope), and pressurized gas chamber [22]. The incident and transmitter bar are made of Ti6Al-4V alloy (13 $\mathrm{mm}$ in diameter and $1900 \mathrm{~mm}$ long) fixed with strain gages in the full Wheatstone bridge circuit connection. The strain gages (1000 $\Omega$ resistance) are mounted on the incident and transmitter bars at a distance of $940 \mathrm{~mm}$ away from the respective bar-specimen interfaces in order to prevent wave interference. The pressurized gas chamber supplies the preset pressure to fire the striker bar which in turn hits the incident bar. With the specimen placed between the incident and the transmitter bar, the deformation of the specimen occurs as a result of the impact force from the incident bar.

The impact force generates elastic wave that travels through the bars and the sample while a fraction of the elastic wave is reflected at the contact surface between the incident bar and the sample. While the elastic wave that propagates through the transmitter bar is captured as transmitted wave by the strain gages attached to the transmitter bar, the incident wave and the reflected wave are captured by the strain gages attached to the incident bar. With the aid of strain conditioners/amplifiers, the elastic wave data captured as voltage-time signal by the strain gages on the incident and transmitter bars were converted to their corresponding load values using the appropriate conversion factor and are storedby the connected mixed signal digital oscilloscope. The material properties determine the amount of reflected wave. The true stress and true strain curve are therefore obtained through the post processing of the stored data using MATLAB code.

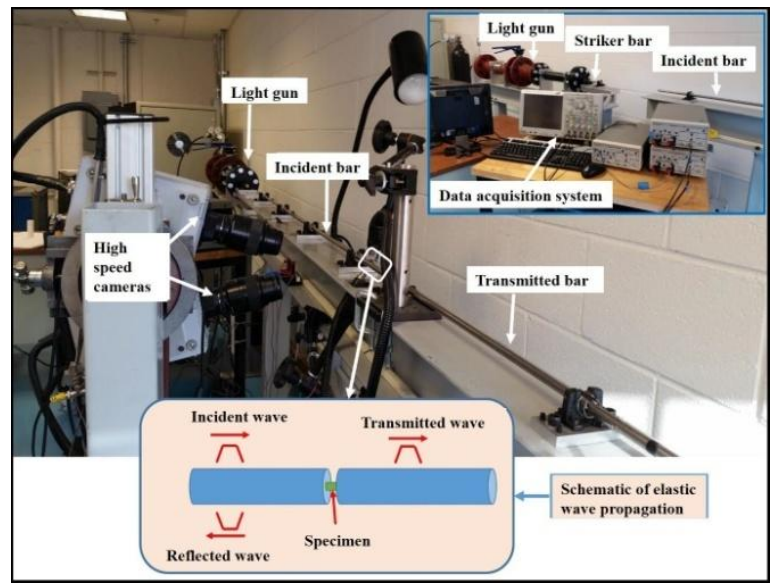

Fig.1. Experimental set-up of SHPB accompanied with high-speed cameras and data acquisition system [23].

AA5052 alloy was prepared through cryo-forging at 2-cycles, 4-cycles, and 6-cycles. To determine the dynamic response of the cryo-forged AA5052 samples when subjected to high strain rate, experiment was conducted using Split-Hopkinson Pressure Bar (SHPB). Although [24] categorized strain rate of $10^{2}$ to $10^{4} \mathrm{~s}^{-1}$ as high strain rate, the dynamic properties of AA5052-CF will be discussed under strain rate that is less or equal to $5000 \mathrm{~s}^{-1}$. The graph obtained from the experiment shows that stress-state equilibrium is achieved during the test if 2-wave stress oscillate above and below the 1-wave stress. This is illustrated in Fig.2. Fig.3 also shows VoltageTime signal of the compression experiment. (4):

Stress $(\sigma)$, strain $(\varepsilon)$, and strain rate $(\dot{\varepsilon})$ in the deformed specimens were calculated using equation $(2)$ through

$$
\sigma=\left(\frac{A_{B}}{A_{S}}\right) E_{B} \varepsilon_{T}
$$




$$
\begin{aligned}
& \varepsilon=-2\left(\frac{C_{B}}{L_{S}}\right) \int_{0}^{t} \varepsilon_{R} d t \\
& \dot{\varepsilon}=-2\left(\frac{C_{B}}{L_{S}}\right) \varepsilon_{R}
\end{aligned}
$$

Where $\varepsilon$ is the strain pulse with the subscript $I, T$, andR signifying incident, transmitted, and reflected strain pulses, respectively. $A_{B}, A_{S}, C_{B}$, and $E_{B}$ are the cross-sectional area of the bar, cross sectional area of the specimen, wave propagation speed in the bars, and elastic modulus of the bar material, respectively [25].

Equation (4), (5) and (6) were used to calculate the strain rate sensitivity (SRS) index, strain-hardening exponent and strain hardening rate respectively.

$$
\begin{aligned}
& m=\frac{\partial \ln \sigma(\varepsilon)}{\partial \ln \dot{\varepsilon}} \\
& n=\frac{\partial \log \sigma}{\partial \log \varepsilon} \\
& \Theta=\frac{d \sigma}{d \varepsilon}=n \frac{\sigma}{\varepsilon_{[\dot{\varepsilon}]}}
\end{aligned}
$$

Where $\sigma$ is the flow stress $(\mathrm{MPa}), \dot{\varepsilon}$ is the strain rate $\left(\mathrm{s}^{-1}\right)$ and $\varepsilon$ is the true strain [23],[26],[27].

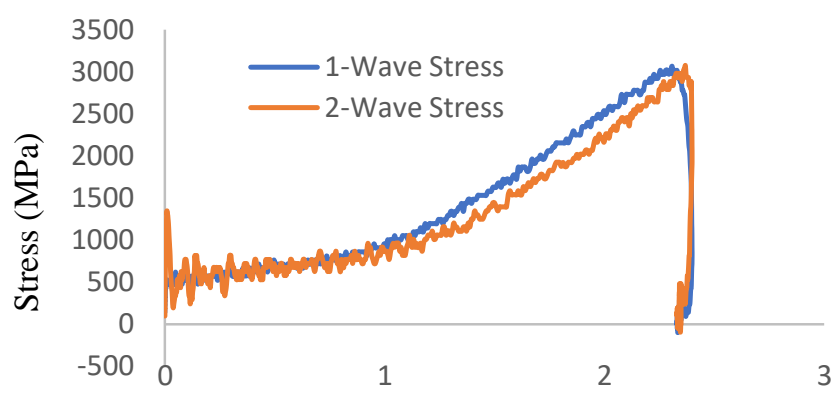

Strain

Fig.2. Plots showing a stress-strain response of AA5052 aluminum specimen including one- and two-wave stress curves and the strain rate.

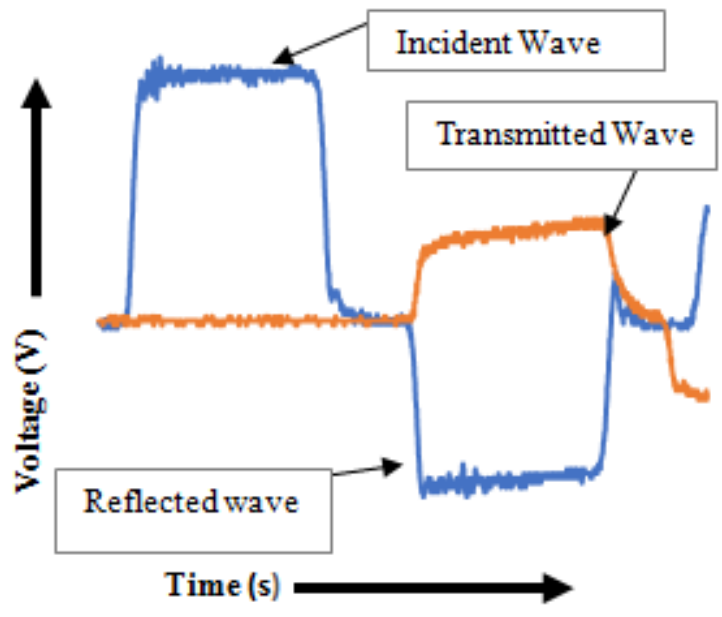

Fig. 3. V-T signal of the compression experiment comprising incident, reflected and transmitted waves. 


\section{Results and Discussion}

\section{True stress-true strain response}

The true stress vs. true strain curves of AA5052-CF aluminum alloys are presented in Fig.4 and Fig. 5. Fig.4 presents the true stress-true strain curves of AA5052-CF alloys that has been processedat 4-cycles while Fig.5represent the true stress-true strain curves of the same alloy that was processed at 6-cycles. It can be observed that the effect of thermal softening is predominant after the yield point for all the true stress-true strain curves. This can be attributed to the dislocation annihilation, dislocation climbing and cross-slip [28]-[30]. The thermal softening effect was continuous unto the point of fracture in both 4-cycles AA5052-CF and 6-cycles AA5052CF.There is strain hardening effect after the initial thermal softening, but the maximum flow stress reached at the second stage strain hardening is lesser than the maximum flow stress of the first stage thereby making the maximum flow stress at the second stage of less importance. The second stage strain hardening is a consequence of dislocation multiplications during the plastic deformation of the materials[31].

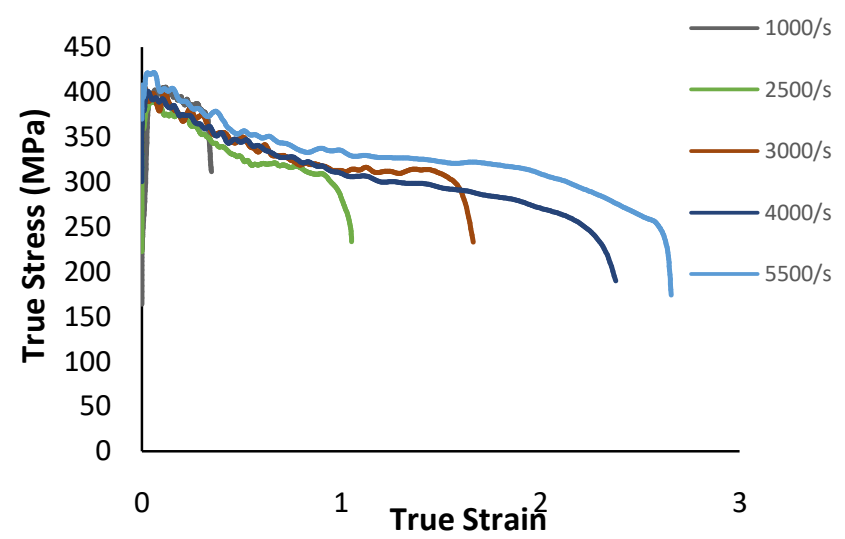

Fig. 4. Dynamic stress-strain curves of AA5052 CF (4 cycles) aluminum alloy under high-strain rate compressive loading.

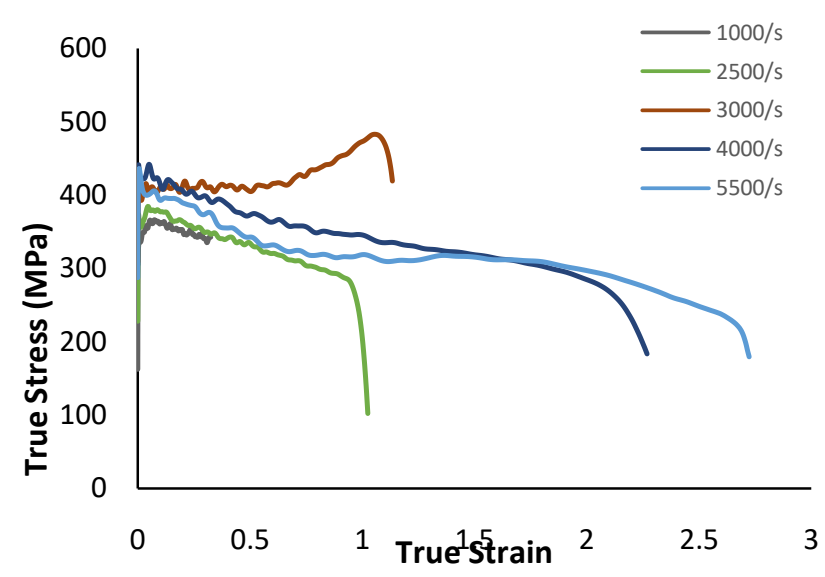

Fig.5.Dynamic stress-strain curves of AA5052 CF (6 cycles) aluminum alloy under high-strain rate compressive loading.

Generally, the final stage of the plastic deformation of aluminum alloys under high strain rate is characterized by drop in the flow stress because of stress collapse from thermal softening[32]. The thermal softening arises from conversion of about $90 \%$ of the plastic work into heat thereby causing thermomechanical instability[33]. The total true strain experienced by the samples at various strain rate increases with the strain rate whilethe effect of strain hardening decreases with strain rate. This observation resonate with the fact the thermal softening is dominant in the deformation process.

\section{Strain Hardening Effect}

The dynamic yield strength and the maximum flow stress of AA5052-CF are presented in Fig.6 and Fig 7.For both yield strength and maximum flow stress, 6-cycles AA5052-CF shows superior properties with the exception of maximum flow stress at $1000 \mathrm{~s}^{-1}$ and $2000 \mathrm{~s}^{-1}$. For both conditions, the yield strength increases with the strain 
rate while the maximum flow stress only show marginal increase with strain rate and in some cases decreased. The dynamic yield strength is $410 \mathrm{MPa}$ and $443 \mathrm{MPa}$ for 4-cycles and 6-cycles, respectively. For 4-cycles, the dynamic yield strength occurs at strain rate of $5000 \mathrm{~s}^{-1}$ while that of 6-cycles occur at $4000 \mathrm{~s}^{-1}$, although the dynamic yield strength for 6-cycles stands at $441 \mathrm{MPa}$ at $5000 \mathrm{~s}^{-1}$ which is very close to that of $4000 \mathrm{~s}^{-1}$. The maximum flow stress is $410 \mathrm{MPa}$ at $5000 \mathrm{~s}^{-1}$ and $494 \mathrm{MPa}$ at $3000 \mathrm{~s}^{-1}$ for 4-cyles and 6-cycles, respectively.

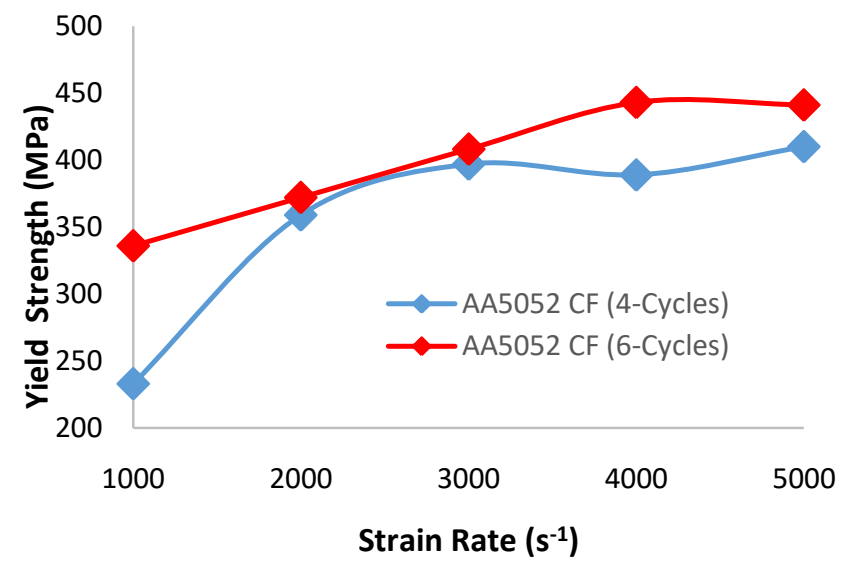

Fig.6. Dynamic yield strength variation of AA5052 CF aluminum alloy under high-strain rate compressive loading.

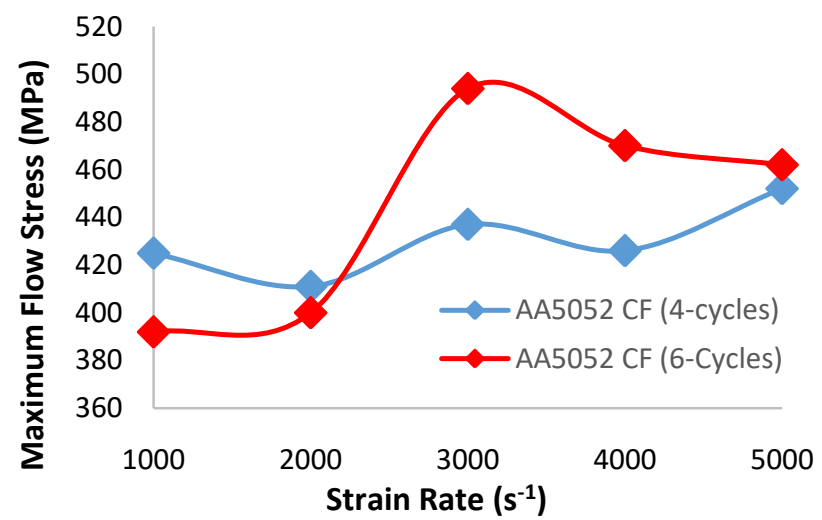

Fig.7. Maximum Flow stress variation of AA5052 CF aluminum alloy under high-strain rate compressive loading.

The strain hardening effect was evaluated by determining the strain hardening exponent and consequently using the strain hardening exponent to plot the plastic flow stress-strain graph and the graph of strain hardening rate against true strain. This study only uses the uniform plastic deformation regions of the true stress-true strain curves obtained at room temperatures to calculate the strain-hardening exponent and the strain hardening rate.

The plots of the logarithm of the true stress versus the logarithm of the true strain for the AA5052-CF are presented in Fig.8 and Fig. 9. The slope of the equation of the linear fit to each curve represents the strain hardening exponent. The strain hardening exponents and other relevant information that was used in calculating the plastic flow stress is extracted from the equation of the linear fit. The strain hardening exponent is highest at $1000 \mathrm{~s}^{-1}$ for both 4-cycles and 6-cycles AA5052-CF. Although it can be said that the strain hardening exponent decreases with strain rate, there are however some instances where it increases. For example, the strain hardening exponent increases from 0.066 at $3000 \mathrm{~s}^{-1}$ to 0.086 at $4000 \mathrm{~s}^{-1}$ in the 6-cycles AA5052-CF samples (Fig.9). The reduction in the strain hardening exponent with strain rate is expected since there is higher impact energy at higher strain rate thus, generating more adiabatic heating in the material during the plastic deformation. It has been earlier said that the adiabatic heating leads to thermal softening which in turn does not favor strain hardening.

The strain hardening exponent decreases with increase in strain rate (Fig. 10). This signifies that thermal softening effect becomes more predominant with increase in strain rate. However, the reverse is the case when it comes to thermal softening rate. With increase in strain rate, the thermal softening rate reduces which directly translate to favoring strain hardening rate. Therefore, this phenomenon is as a result of dislocation multiplications which reduces the effect of thermal softening. This effect applies to both 4-cylces and 6-cycles AA5052-CF.The strain hardening exponent is also relatively higher in 4-cycles AA5052-CF when compared with 6-cycles 
AA5052-CF. This is a direct consequence of the fact that 6-cycles AA5052-CF aluminum alloy undergoes more initial work hardening than 4-cycles AA5052-CF. Therefore, the result of the experiment conforms with the anticipated expectation of having lesser strain hardening in 6-cycles AA5052-CF.

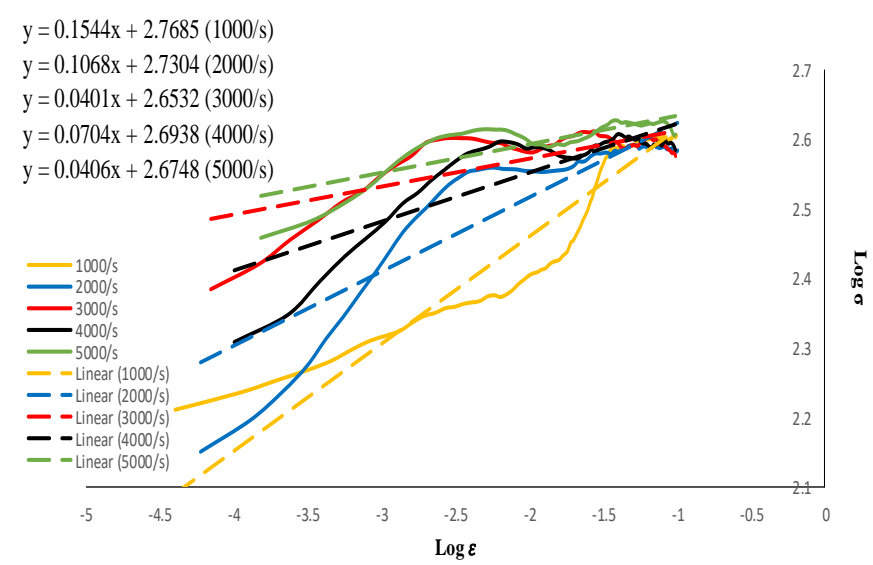

Fig.8. Logarithmic curves of true stress and true strain of AA5052-CF (4 cycles) aluminum alloy within the homogenous deformation region.

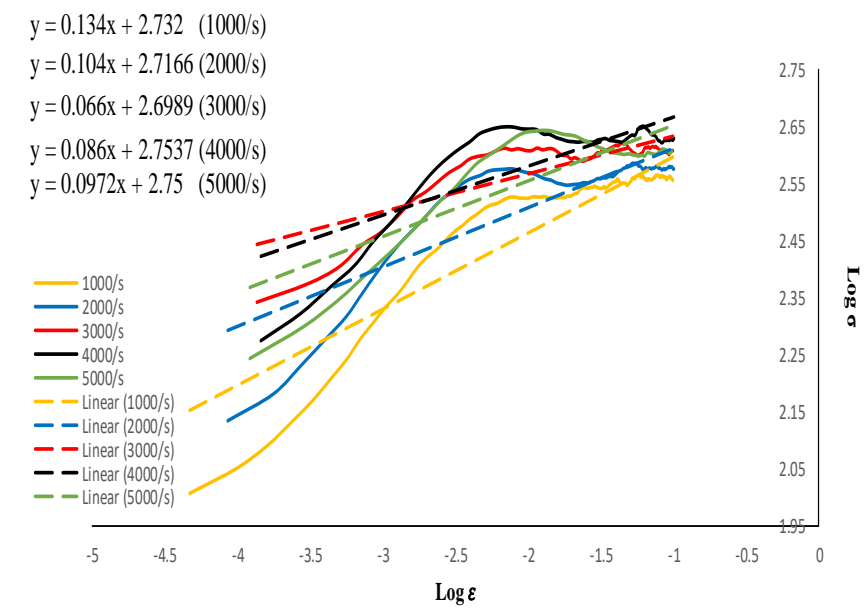

Fig.9. Logarithmic curves of true stress and true strain of AA5052-CF (6-cycles) aluminum alloy within the homogenous deformation region.

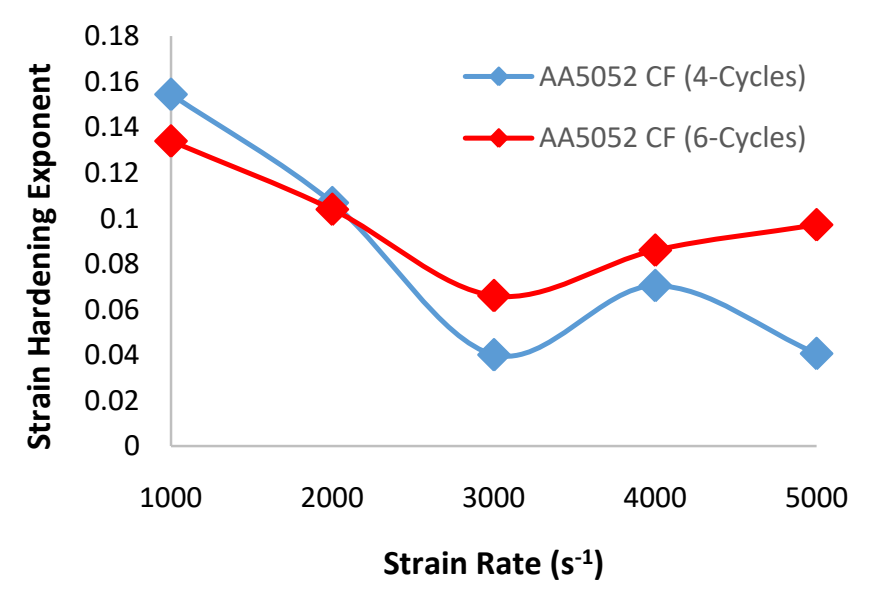

Fig. 10. Strain hardening exponent at of AA5052-CF at different strain rates.

The plastic flow stress was computed using the Hollomon's power law [34] which is given as;

$\sigma=K \varepsilon^{n}$ 
Where $\mathrm{n}$ is the strain hardening exponent and $\mathrm{K}$ is the strength index or strength coefficient. The plastic flow stress-true strain curves at different strain rates are presented in Fig.11 and Fig 12. From Fig. 11, it is clear that strain hardening effect in 4-cycles AA5052-CF is higher at lower strain rate since the plastic flow stress curve becomes steeper with increase in strain rate. This also confirms the earlier discussion where it was said that the thermal softening effect increases with increasing strain rate. This indicates that the strain hardening is not favored with increasing strain rate. However, a slightly different result was obtained for 6-cycles AA5052-CF where the plastic flow stress increases with increase in strain rate up to $5000 \mathrm{~s}^{-1}$ (Fig. 12).

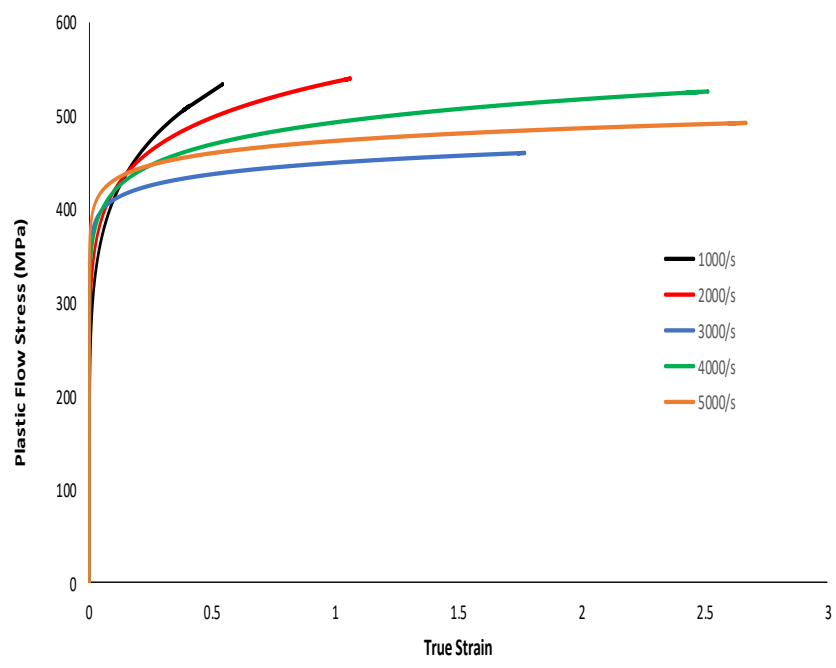

Fig.11. Strain-hardening response of AA5052 CF (4-Cycles) aluminum alloys when subjected to high strain rate.

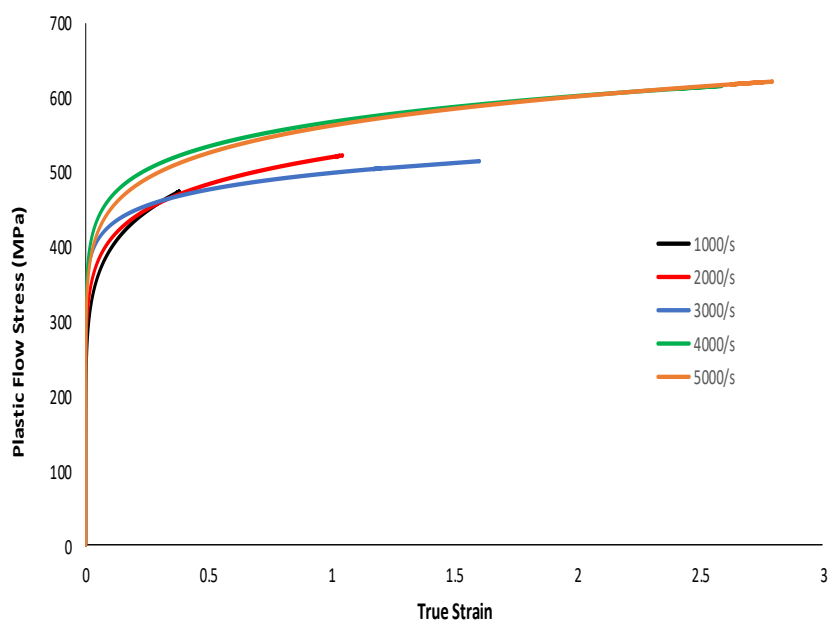

Fig.12. Strain-hardening response of AA5052 CF (6-Cycles) aluminum alloys when subjected to high strain rate.

Figure 13 to Figure 17 compare the strain hardening rate or thermal softening rate of 4-cycles AA5052-CF and 6-cycles AA5052-CF at $1000 \mathrm{~s}^{-1}, 2000 \mathrm{~s}^{-1}, 3000 \mathrm{~s}^{-1}, 4000 \mathrm{~s}^{-1}$, and 5000/s respectively. At $1000 \mathrm{~s}^{-1}$ and $2000 \mathrm{~s}^{-1}$, there is negligible difference between the thermal softening rate of 4-cyles AA5052-CF and 6-cycles 5052-CF. However, further increase in strain rate to $3000 \mathrm{~s}^{-1}, 4000 \mathrm{~s}^{-1}$, and $5000 \mathrm{~s}^{-1}$ shows that the thermal softening rate is higher in 6-cycles AA5052-CF. This is understandable because the 6-cycles AA5052-CF has more work hardening during the material processing [35]. 


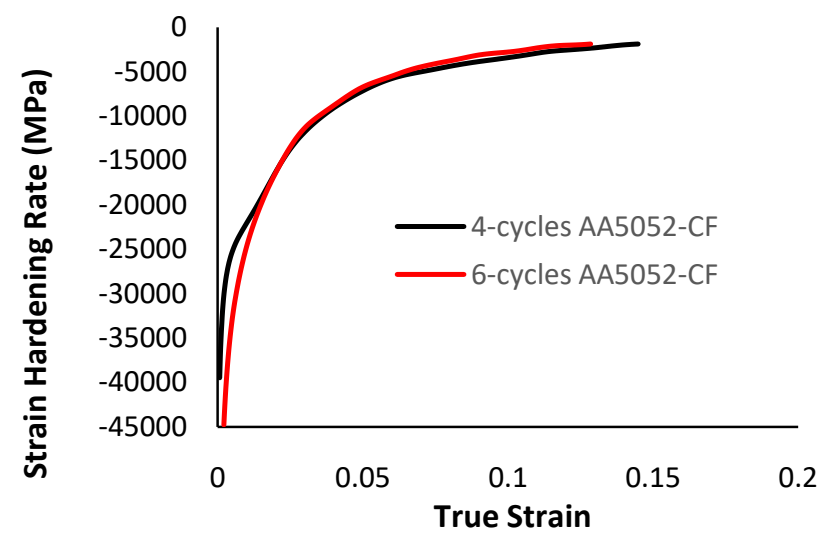

Fig. 13. Strain hardening rate vs true strain for AA5052-CF at $1000 \mathrm{~s}-1$.

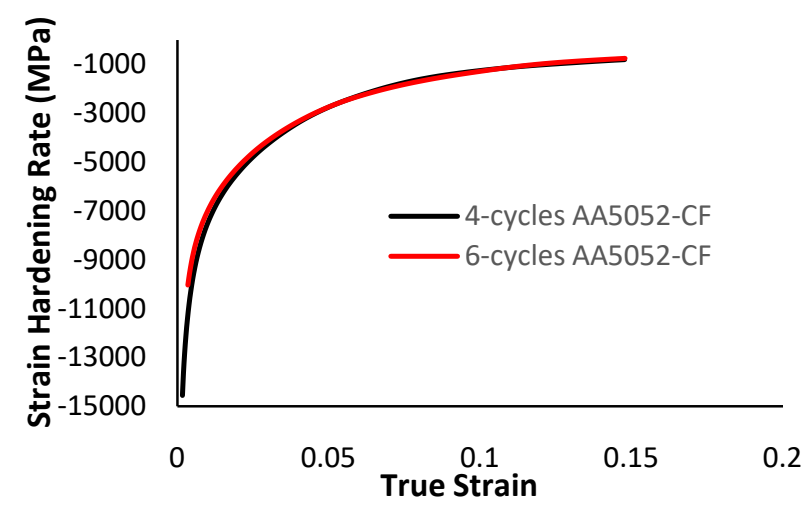

Fig.14. Strain hardening rate vs true strain for AA5052-CF at 2000 s-1.

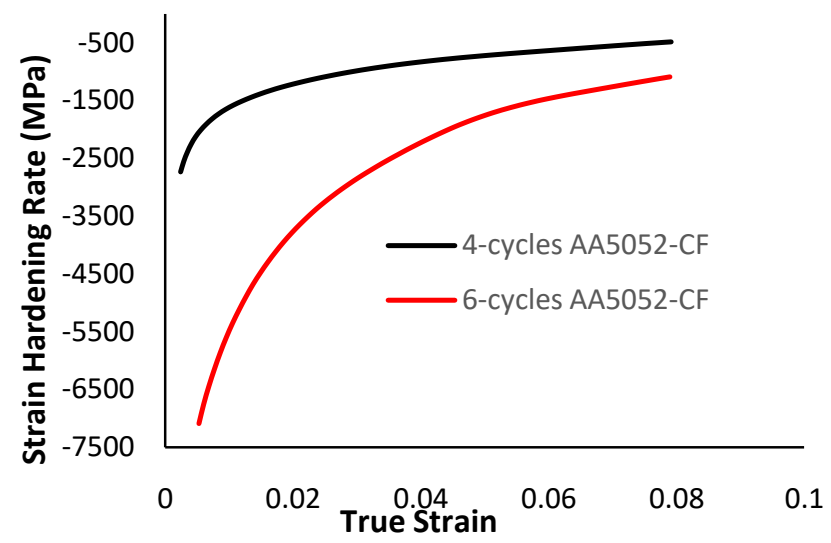

Fig. 15. Strain hardening rate vs true strain for AA5052-CF at $3000 \mathrm{~s}-1$. 


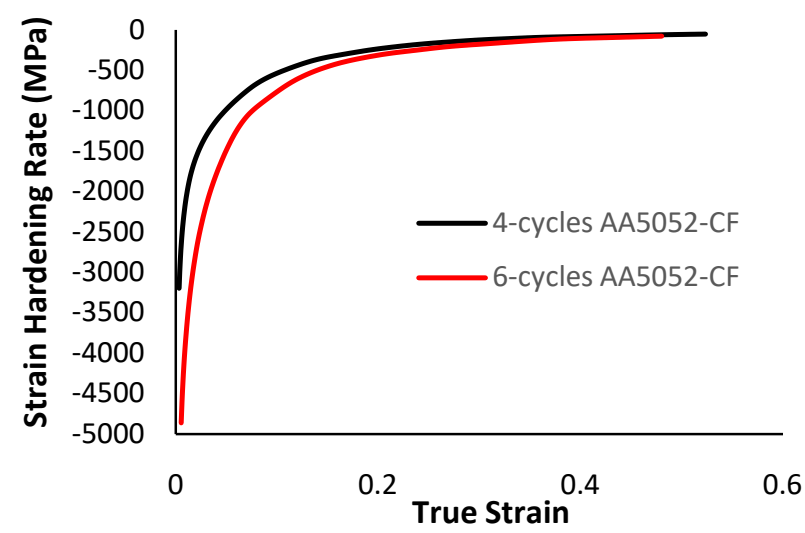

Fig. 16. Strain hardening rate vs true strain for AA5052-CF at $4000 \mathrm{~s}-1$.

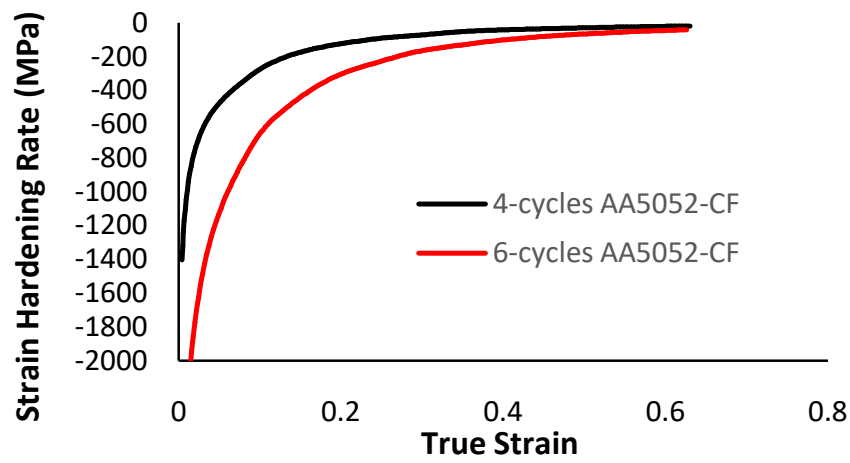

Fig. 17.Strain hardening rate vs true strain for AA5052-CF at 5000 s-1.

The strain hardening behavior of 4-cycles and 6-cycles AA5052-CF was studied to further understand the strengthening mechanism and strengthening process during the plastic deformation. The strain hardening rate curve in Fig. 18 and Fig. 19 for 4-cycles AA5052-CF and 6-cycles AA5052-CF respectively were produced using equation 7. The strain hardening rate curve fell on the negative side of the vertical axis because the thermal softening effect dominates the plastic deformation. Since the thermal softening effect dominates, the strain hardening rate can be discussed in term of the thermal softening effect.

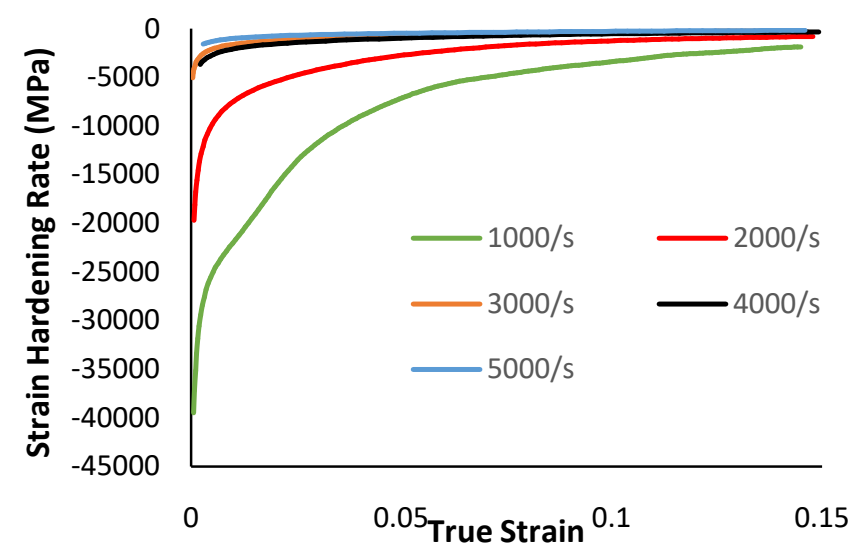

Fig.18. Strain hardening rate vs true strain for 4-cycle AA5052-CF. 


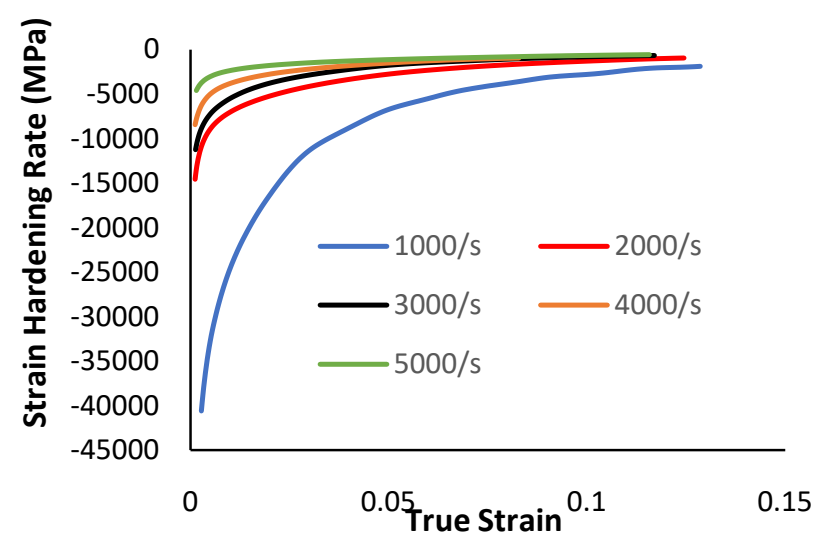

Fig.19. Strain hardening rate vs true strain for 6-cycle AA5052-CF.

\section{EBSD Analysis of the Deformed Specimen}

The EBSD maps of the deformed AA5052-CF alloys are shown in Fig.20. Fig 20 (a) and Fig 20 (b) represent the 4-cylcels and 6-cycles cryo-forged specimen respectively. The radial direction of the sample coincides with the vertical axis while the direction of forging direction (tangential direction) is along the horizontal axis. The average grain size of the of the 4-cycles AA5052-CF alloys remains at $900 \mathrm{~nm}$ while that of 6-cycles AA5052$\mathrm{CF}$ is approximately $\sim 700 \mathrm{~nm}$. The AA5052 CF (4-cycles) has a higher grain size because it undergoes less severe plastic deformation during the material processing. The presence of a more approximately homogeneous grain size in the 6-cycles AA5052-CF samples is due to the higher plastic strain that is stored in it when compared to the 4-cycles AA5052-CF samples.

\section{Conclusions}

The dynamic response of cryo-forged AA5052 at 4-cycles and 6-cycles was investigated using compression testing at high strain rates. The compression testing was conducted using the Split-Hopkinson Pressure Bar (SHPB). The following conclusions can be made from the analysis that have been done so far;

- The deformation process is dominated by thermal softening and less of strain hardening. The thermal softening sets in when the materials have undergone less than 0.1 strain and continues till the end of the deformation process.

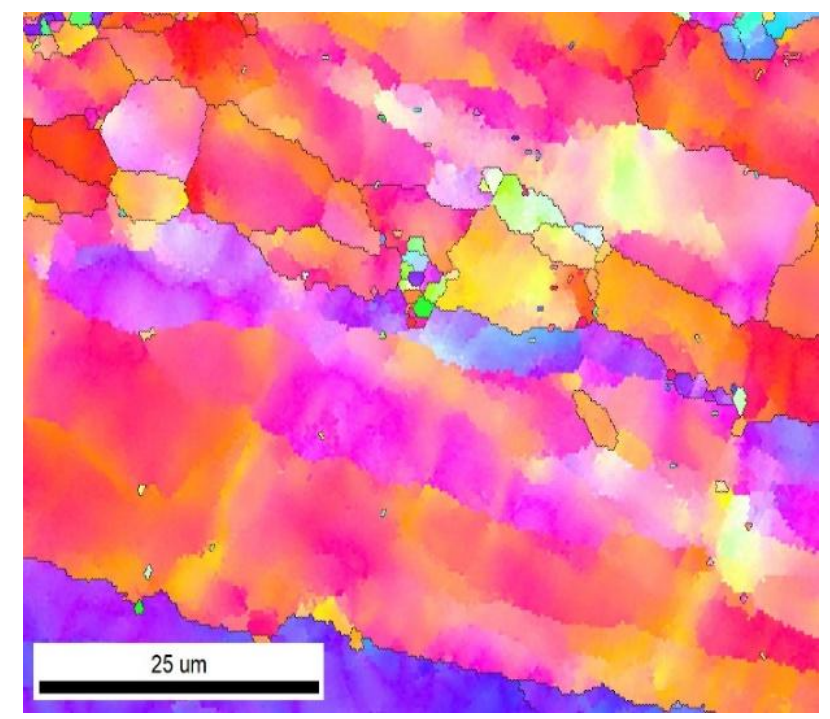

(a) 


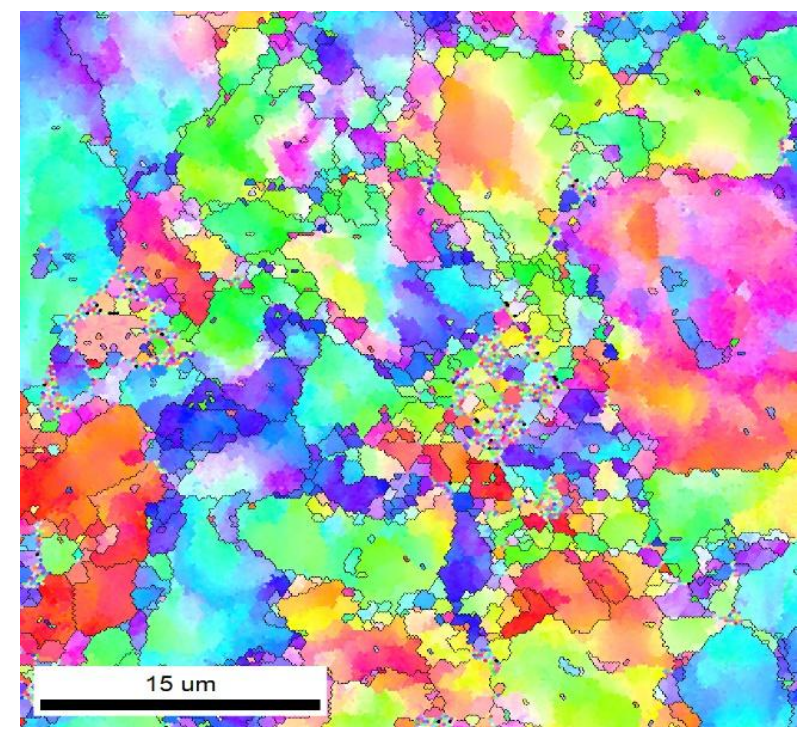

(b)

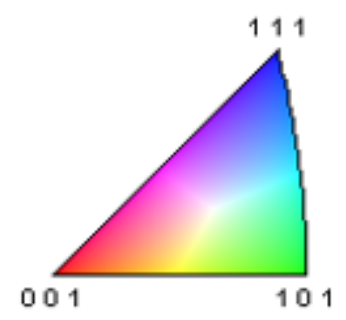

(c)

Fig.20EBSD maps of the (a) 4-cycles and (b) 6-cycles AA5052-CF deformed specimens. (c) Color code map.

- Except at lower strain rates $\left(\dot{\varepsilon} \leq 2000 \mathrm{~s}^{-1}\right)$, the 6-cycles AA5052-CF have superior properties in term of dynamic yield strength, maximum flow stress, plastic flow stress and strain hardening exponent. However, despite the fact that 6-cycles AA5052-CF has higher strain hardening exponents, the thermal softening rate is considerably higher in 6-cycles AA-5052-CF at $\dot{\varepsilon}>2000 \mathrm{~s}^{-1}$.

\section{Acknowledgments}

Financial support for this project was provided by the Air Force Research Laboratory through the Diverse collegiate R\&D program (contract \# FA8650-17-2-2243) under the direct supervision of Dr. Onome ScottEmuakpor. We also thank Mr. James Griffins of the Howard University Nanotechnology Center for his technical support in materials characterization

\section{References}

J. William D. Callister and D. G. Rethwisch, "Materials Science and Engineering: An Introduction 9E," John Wiley Sons, Inc, vol. 9, no. 6058, pp. 266-267, 2014.

R. N. Harsha, V. Mithun Kulkarni, and B. Satish Babu, "Severe Plastic Deformation A Review," Mater. Today Proc., vol. 5, no. 10, pp. 22340-22349, 2018.

Y. Estrin and A. Vinogradov, "Extreme grain refinement by severe plastic deformation: A wealth of challenging science," Acta Mater., vol. 61, no. 3, pp. 782-817, 2013.

Y. Cao, S. Ni, X. Liao, M. Song, and Y. Zhu, "Structural evolutions of metallic materials processed by severe plastic deformation,” Mater. Sci. Eng. R Reports, vol. 133, no. June, pp. 1-59, 2018.

P. Kumar, M. Kawasaki, and T. G. Langdon, "Review: Overcoming the paradox of strength and ductility in ultrafine-grained materials at low temperatures," J. Mater. Sci., vol. 51, no. 1, pp. 7-18, 2016.

R. B. Figueiredo and T. G. Langdon, "Fabricating ultrafine-grained materials through the application of severe plastic deformation: A review of developments in Brazil," J. Mater. Res. Technol., vol. 1, no. 1, pp. 55-62, 2012.

R. Z. Valiev, R. K. Islamgaliev, and I. V. Alexandrov, Bulk nanostructured materials from severe plastic deformation, vol. 45 , no. 2. 2000. 
R. Z. Valiev, Y. Estrin, Z. Horita, T. G. Langdon, M. J. Zehetbauer, and Y. Zhu, "Producing Bulk UltrafineGrained Materials by Severe Plastic Deformation: Ten Years Later,” Jom, vol. 68, no. 4, pp. 1216-1226, 2016.

D. J. Alexander, "New methods for severe plastic deformation processing," J. Mater. Eng. Perform., vol. 16, no. 3, pp. 360-374, 2007.

Y. Zhu, R. Z. Valiev, T. G. Langdon, N. Tsuji, and K. Lu, "Processing of nanostructured metals and alloys via plastic deformation,” MRS Bull., vol. 35, no. 12, pp. 977-981, 2010.

T. G. Langdon, "Twenty-five years of ultrafine-grained materials: Achieving exceptional properties through grain refinement," ACTA Mater., 2013.

Y. Huang and T. G. Langdon, "Advances in ultrafine-grained materials," Biochem. Pharmacol., vol. 16, no. 3, pp. 85-93, 2013.

A. Babu, V. Swami, N. Gurugubelli, and S. Bandaru, "Severe plastic deformation of AA 5083 and copper bimetallic metal," SN Appl. Sci., no. August, 2020.

A. P. Zhilyaev, "Orientation imaging microscopy of ultrafine-grained nickel,” vol. 46, pp. 575-580, 2002.

A. P. Zhilyaev, G. V Nurislamova, M. D. Baro, J. A. Szpunar, and T. G. Langdon, "Experimental parameters influencing grain refinement and microstructural evolution during high-pressure torsion," vol. 51, pp. 753765,2003

T. G. Langdon, “A comparison of microstructures and mechanical properties in a $\mathrm{Cu}-\mathrm{Zr}$ alloy processed using different SPD techniques,” pp. 4653-4660, 2013.

N. Rangaraju, T. Raghuram, B. V. Krishna, K. P. Rao, and P. Venugopal, "Effect of cryo-rolling and annealing on microstructure and properties of commercially pure aluminium," vol. 398, pp. 246-251, 2005.

S. S. L. Vendra, S. Goel, N. Kumar, and R. Jayaganthan, "A study on fracture toughness and strain rate sensitivity of severely deformed Al 6063 alloys processed by multiaxial forging and rolling at cryogenic temperature," Mater. Sci. Eng. A, vol. 686, pp. 82-92, 2017.

M. Das, T. K. Pal, and G. Das, "Effect of aging and cryo rolling on microstructural characterization and mechanical properties of precipitation hardenable 6063Al alloy,” Mater. Sci. Eng. A, vol. 552, pp. 31-35, 2012.

ASM International, A.S.M. International, Asm Handbook: Properties and Selection: Nonferrous Alloys and Special-Purpose Materials (Asm Handbook) VOL. 2, vol. 2. Materials Park, Ohio: ASM International, 1990.

J. R. Davis and M. Park, Alloying: understanding the basics, vol. 39, no. 09. 2013.

Y. Chen, A. H. Clausen, O. S. Hopperstad, and M. Langseth, "Application of a split-Hopkinson tension bar in a mutual assessment of experimental tests and numerical predictions," Int. J. Impact Eng., vol. 38, no. 10, pp. 824-836, 2011.

A. T. Olasumboye, G. M. Owolabi, A. G. Odeshi, N. Yilmaz, and A. Zeytinci, "Dynamic Behavior of AA2519T8 Aluminum Alloy Under High Strain Rate Loading in Compression,” J. Dyn. Behav. Mater., 2018.

T. R. Kaliat, "High Rates an," in Springer Handbook of Experimental Solid Mechanics, New York: Springer, 2008, pp. 929-959.

G. M. Owolabi, D. T. Bolling, A. G. Odeshi, H. A. Whitworth, N. Yilmaz, and A. Zeytinci, "The Effects of Specimen Geometry on the Plastic Deformation of AA 2219-T8 Aluminum Alloy Under Dynamic Impact Loading," J. Mater. Eng. Perform., 2017.

A. Olasumboye, G. Owolabi, A. Odeshi, A. Zeytinci, and N. Yilmaz, "Dynamic Response and Microstructure Evolution of AA2219-T4 and AA2219-T6 Aluminum Alloys,” J. Dyn. Behav. Mater., 2017.

A. Azimi, G. M. Owolabi, H. Fallahdoost, N. Kumar, and G. Warner, "Dynamic Failure Investigation in Ultrafine Grained AA2219: Mechanical and Microstructural Analysis,” Met. Mater. Int., 2019.

B. Dodd and Y. Bai, "Introduction," Adiabatic Shear Localization, pp. 1-20, 2012.

J. Luo and M. Q. Li, "Strain rate sensitivity and strain hardening exponent during the isothermal compression of Ti60 alloy,” Mater. Sci. Eng. A, vol. 538, pp. 156-163, 2012.

V. Pare, S. Modi, and K. N. Jonnalagadda, "Thermo-mechanical behavior and bulk texture studies on AA5052H32 under dynamic compression,” Mater. Sci. Eng. A, vol. 668, pp. 38-49, 2016.

Z. Y. Liang, X. Wang, W. Huang, and M. X. Huang, "Strain rate sensitivity and evolution of dislocations and twins in a twinning-induced plasticity steel," Acta Mater., vol. 88, pp. 170-179, 2015.

T. Wang et al., "A thermo-elastic-plastic phase-field model for simulating the evolution and transition of adiabatic shear band. Part II. Dynamic collapse of thick-walled cylinder," Eng. Fract. Mech., vol. 231 , no. April, 2020.

Y. Zhou, Q. Fan, X. Liu, D. Wang, X. Zhu, and K. Chen, "Multi-scale crystal plasticity finite element simulations of the microstructural evolution and formation mechanism of adiabatic shear bands in dual-phase Ti20C alloy under complex dynamic loading,” J. Mater. Sci. Technol., vol. 59, pp. 138-148, 2020.

C. Zener and J. H. Hollomon, "Effect of strain rate upon plastic flow of steel," in Journal of Applied Physics, 2018, vol. 5, no. 1, pp. 22-32.

G. Faraji, H. S. Kim, and H. T. Kashi, Severe Plastic Deformation Methods for Bulk Samples. 2018. 